\title{
EFFECTS OF A COMPETITIVE TRIATHLON ON PLASMA CONCENTRATIONS OF TRYPTOPHAN AND BRANCHED-CHAIN AMINO ACIDS
}

Jorge OSORIO* Hugo DONOSO**

\section{SUMMARY}

The aim of this work was to determine the acute responses of tryptophan and branched chain amino acids to a triathlon competition. Fourteen male triathletes were studied. All took part in a international triathlon race consisting of $1,5 \mathrm{~km}$ swimming, $40 \mathrm{~km}$ biking and $10 \mathrm{~km}$ running. Venous blood samples were drawn before $(-24 \mathrm{~h})$ and after $(15 \mathrm{~min})$ the triathlon. Plasma concentration of branched chain amino acids and total and free tryptophan were determined. Branched chain amino acids decreased from $463 \pm 108.3$ to $364 \pm 98.9 \mathrm{~mol} / \mathrm{L}(\mathrm{p}<0.03)$. Free tryptophan increases from 9.2 to 16.3 $\mathrm{mol} / \mathrm{L}(\mathrm{p}<0.006)$. Furthermore the ratio of free trytophan to branched chain amino acids increased from $2.07 \pm 0.48$ to $4.24 \pm 0.79(p<0.001)$. This increases the rate of transport of tryptophan accross the blood-brain barrier and also increases the rate of synthesis of 5-hydroxytryptamine in the central nervous system. A high presence of 5-hydroxytryptamine in the brain develops physical and mental fatigue during the triathlon. This data support the participation of amino acids in fatigue process during triathlon.

UNITERMS: Fatigue; Triathlon; Tryptophan.

The triathlon has become one of the most popular endurance events (Osorio et alii, 1990; Osorio \& Donoso, 1990). Diversity of training is indoubtedly a major reason, but the distances of competition also account for the popularity of this sport.

In the order to be a succesfull triathlete in this sport, fatigue should be delayed in extreme. Certain amino acids can participate in this process. In fact, although amino acids are the precursors for protein synthesis, they also act as precursors for certain neurotransmitters. For example, tryptophan is converted in the brain to a neurotransmitter known as 5-hydroxytryptamine, which play a role in influencing mood.

The ratio in the bloodstream of the levels of tryptophan to branched chain amino acids could control the rate of entry of tryptophan into the brain. This fact affects the concentrations of 5hydroxytryptamine and hence behaviour. A reduction in the concentration of branched amino acids in the

\footnotetext{
* Exercise and Sport Research Institute, Arizona State University.

** Centro de Investigaciones en Salud Ocupacional, Asociacion Chilena de Seguridad.
} 
blood, caused by a rise in the rate of uptake by muscle, will lead to an increase in the ratio of tryptophan to branched chain amino acids in the blood. This will favour the entry of tryptophan into the brain and increase the level of 5-hydroxytryptamine in the brain and this could result in central fatigue.

Recently, Blomstrand et alii (1988) reported a decrease in the plasma concentration of branched chain amino acids, and a rise of free tryptophan after a marathon running. Therefore, they found a rise in the ratio free tryptophan/branched chain amino acids. The authors suggested that this condition should lead to an elevated concentration of 5-hydroxytryptamine in specific areas of the brain. This may be responsible for the development of physical, and/or mental fatigue during prolonged exercise. In fact, a recent study reported that endurance exercise in rats increases the concentration of 5hydroxytryptamine in two areas of the brain (Blomstrand et alii, 1989).

The aim of this study was to examine the responses of branched-chain amino acids and tryptophan to an acute prolonged exercise bout. Special emphasis will be point on central fatigue.

\section{MATERIAL AND METHODS}

Fourteen healthy male athletes who competed in a triathlon consisting of $1.5 \mathrm{~km}$ swimming, $40 \mathrm{~km}$ biking and $10 \mathrm{~km}$ running, were studied. Their physical characteristics are summarized in TABLE 1. Body fat was evaluated by measuring 4 skinfold (biceps, triceps, subescapular, suprailiac) according to Durnin \& Womersley (1974). VO2 max was measured on a motor driven treadmill (Quinton Instruments). Subjects were fully informed of all aspects of the study, and each signed a statement of informed consent.

The subjects averaged 4.2 years of recreational or competitive triathlon experience.

Blood samples were collected from an antecubital vein 24 hours prior to the triathlon (following a 12 hours fast and between 7 and 8 hours A.M.) and within 15 minutes after finishing the race. Blood samples were centrifugated for 10 minutes, then the plasma was separated and frozen at $0-4^{\circ} \mathrm{C}$ until analysis.

Plasma concentration of branched-chain amino acids was measured according to Livesey \& Lund (1980). Plasma free tryptophan was separated from albumin-bound tryptophan by the method of Bloxam et alii (1977). Total plasma tryptophan was determined by the method of Bloxam \& Warren (1974).

0.05 .

All variables were analyzed using paired $t$ test. Significance was accepted at a level of $p<$

TABLE 1 Physical characteristics of subjects.

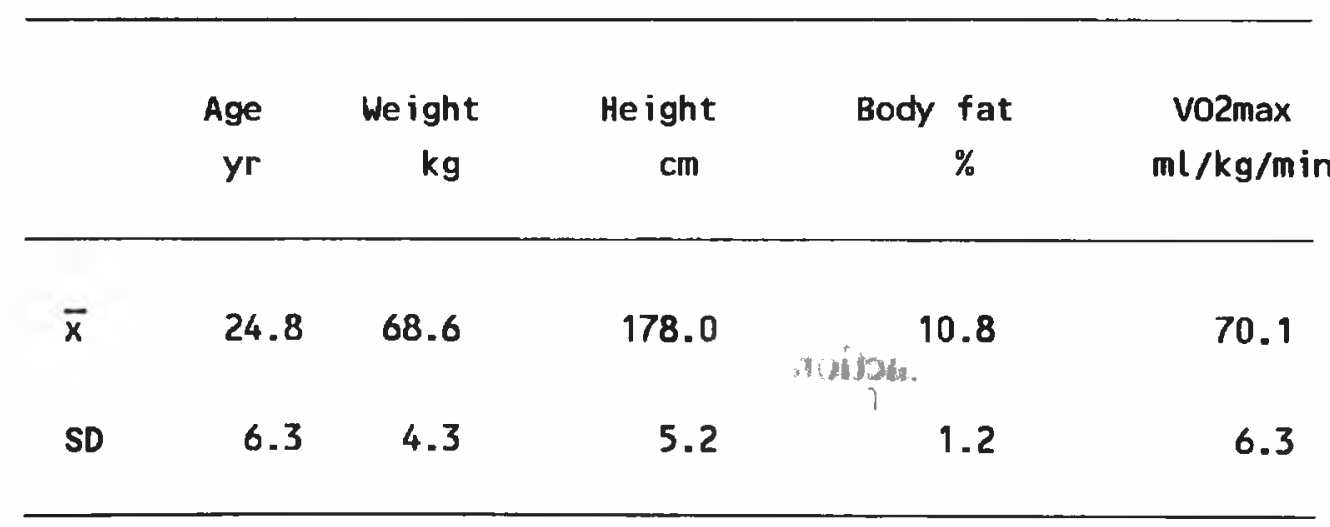




\section{RESULTS}

TABLE 2 summarizes the modifications of the competitive triathlon on plasma concentrations of branched chain amino acids, free and total tryptophan, and the ratio of percent free tryptophan to branched chain amino acids.

Branched chain amino acids decreased from $463 \pm 108.3 \mathrm{~mol} / \mathrm{L}$ at pre triathlon to $364 \pm$ $98.9 \mathrm{~mol} / \mathrm{L}$ at post triathlon $(\mathrm{p}<0.03)$.

Total tryptophan did not modified significantly. However, free tryptophan increased $77.2 \%$, from $9.2 \pm 2.15 \mathrm{~mol} / \mathrm{L}$ to $16.3 \pm 4.45 \mathrm{~mol} / \mathrm{L}(\mathrm{p}<0.006)$.

The ratio of free tryptophan to branched chain amino acids increased from $2.07 \pm 0.48$ at pre triathlon to $4.24 \pm 0.79$ at post triathlon $(p<0.001)$.

TABLE 2 Modifications of plasma concentrations of branched chain amino acids, free and total tryptophan, and percent of free tryptophan to branched chain amino acids ratio before and after the triathlon. Values are expressed in $\mathrm{mol} / \mathrm{L}$, with mean and SD.

\begin{tabular}{|c|c|c|c|c|c|}
\hline CONDITION & & $\begin{array}{l}\text { HED CHAIN } \\
\text { IO ACIDS }\end{array}$ & TOTAL & FREEE & \%FREE T/BCAA \\
\hline Pre-triathlon & $\bar{x}$ & 463 & 56.7 & 9.2 & 2.07 \\
\hline SD & & 108.3 & 13.1 & 2.15 & 0.48 \\
\hline Post-triathlon & $\bar{x}$ & $364^{*}$ & 58.3 & $16.3^{* *}$ & $4.24 * * *$ \\
\hline SD & & 98.9 & 9.7 & 4.45 & 0.79 \\
\hline
\end{tabular}

\%FREE T BCAA means percent of free tryptophan to branched chain amino acids ratio.

* $p<0.03$

$\star \star p<0.006$

$\star \star \star p<0.001$

\section{DISCUSSION}

The purpose of this work was to determine the acute effects of a triathlon race on plasma concentration of amino acids related with central fatigue.

As was stated amino acids act as precursors for neurotransmitters within the central nervous system. Thus any change in plasma concentration of a specific amino acid could affects the rate of synthesis of a neurotransmitter. For example, a rise in the plasma concentration of tryptophan may influence the rate of synthesis of 5-hydroxytryptamine in the brain. Therefore, changes in the concentrations of other plasma amino acids may influence the rate of transport of tryptophan across the blood-brain barrier, specially the change in the plasma concentration of the branched chain amino acids (Blomstrand et alii, 1988; Ferstrom \& Faller, 1978). 
Blomstrand et alii (1988) studied 22 subjects who participated in a marathon race. They found a significant decrease in the plasma concentration of branched-chain amino acids.

In our work we found a $21.4 \%$ decrease in the plasma concentration of branched chain amino acids. This data are in agreement with previous research of Blomstrand et alii (1988), Decombaz et alii (1979) and Refsum et alii (1979), but in contrast with Ahlborg et alii (1974) and Felig \& Wahren (1971). The reasons for these discrepancies may be the different protocols of exercise in the last studies. In fact, either low-intensity exercise of long duration, more brief or high intensity exercise was applied.

The ratio in the bloodstream of the concentrations of tryptophan to branched chain amino acids can control the rate of entry of tryptophan into the brain and this can, therefore, affect the level of 5-hydroxytryptamine. A reduction in the concentration of branched chain amino acids in the blood will lead to a rise in the ratio of tryptophan to branched chain amino acids in the blood and, hence, favour the entry of tryptophan into the brain. This will increase the concentration of the 5-hydroxytryptamine in the brain and this could result in central fatigue.

Blomstrand et alii (1988) reported a rise in the plasma concentration ratio of free tryptophan/branched chain amino acids after a marathon race.

In the present work we found also a significant increase of concentration ratio of $\%$ free tryptophan to branched chain amino acids $(p<0.001)$.

This should lead to a rise in the rate of transport of tryptophan across the blood-brain barrier and hence a marked increase in the rate of synthesis of 5-hydroxytryptamine in the brain. This situation increases the brain concentration of 5-hydroxytryptamine and it could result in central fatigue. It might make effort to maintain physical activity that is much more difficult.

In conclusion our work demonstrates that a triathlon decreased the plasma concentration of branched chain amino acids, and increased tryptophan. Furthermore, the ratio of $\%$ free tryptophan to branched chain amino acids rised after the triathlon. This change possibly increases the rate of transport of tryptophan accross the blood-brain barrier and also rises the rate of synthesis of 5-hydroxytryptamine in the brain. An elevated concentration of 5-hydroxytryptamine in the brain develops physical and mental fatigue during the triathlon. This data could support a new approach to central fatigue.

\section{REFERENCES}

AHLBORG, G. et alii. Substrate turnover during prolonged exercise in man. Journal of Clinical Investigation, v.53, p.1080-90, 1974.

BLOMSTRAND, E. et alii. Changes in plasma concentrations of aromatic and branched chain amino acids during sustained exercise in man and their possible role in fatigue. Acta Physiologica Scandinavica, v.133, p.115-21, 1988.

BLOMSTRAND, E. et alii. Effetcs of a sustained exercise on plasma amino acid concentrations and on 5hydroxytryptamine metabolism in six different brain regions in the rat. Acta Physiologica Scandinavica, v.136, p. 473-81, 1989.

BLOXAM, D.L.; WARREN, W.H. Error in the determination of tryptophan by the method of Denckla and Dewey. A revised procedure. Annals of Biochemistry, v.60, p.621-5, 1974.

BLOXAM, D.L. et alii. A simple apparatus for ultrafiltration of small volumes: application to the measurement of free and albumin-bound tryptophan in plasma. Annals of Biochemistry, v.83, p.130-42. 1977.

DÉCOMBAZ, J. et alii. Biochemical changes in a $100 \mathrm{~km}$ run: free amino acids, urea, and creatinine. European Journal of Applied Physiology, v.41, p.61-72, 1979.

DURNIN, J.V.G.A.; WOMERSLEY, J. Body fat from total body density and its estimation from skinfolds thickness: measurements in 481 men and women aged 16 to 72 years. British Journal of Nutrition, v.32, p.66-72, 1974.

FELIG, P.; WAHREN, J. Amino acid metabolism in exercising man. Journal of Clinical Investigation, v.50, p.2703-14, 1971. 
FERNSTROM, J.D.; FALLER, D.V. Neutral amino acids in the brain: changes in response to food ingestion. Journal of Neurochemistry, v.30, p.1531-8, 1978.

LIVESEY, G.; LUND, P. Enzimatic determination of branched-chain amino acids and 2-oxoacids in rat tissues. Biochemical Journal, v.188, p.885-90, 1980.

OSORIO, J. et alii. Marcadores enzimáticos de daño muscular después de una competencia de triatlón. Archivos de la Sociedad Chilena de Medicina del Deporte, v.35, p.98-107, 1990.

OSORIO, J.; DONOSO, H. Consideraciones fisiológicas sobre rendimiento deportivo en triatletas. Educación Física-Chile, v.222, p.15-8, 1990.

REFSUM, H.E. et alii. Changes in plasma amino acid distribution and urine amino acids excretion during prolonged heavy exercise. Scandinavian Journal of Clinical and Laboratory Investigation, v.39, p.407-13, 1979.

Recebido para publicação em: 19/07/91

Reapresentado em: 03/05/93

We wish express sincerely acknowledgments to subjects participing in our study, to Mr. Manuel Riquelme for his technical contribution to this work.

ENDEREÇO: Jorge Osorio

Martinez de Rozas, 3886

Santiago - CHILE 